\title{
IL28B-Gene Polymorphisms (rs12979860) in HCV Liver Parenchymal changes legitimize Screening for SNPs before DAAs Therapy
}

\author{
Mohamed Darwish Ahmed Abd Alla ( $\nabla$ darwish0716@azhar.edu.eg) \\ Al-Azhar University Faculty of Medicine https://orcid.org/0000-0002-3601-6907 \\ Reham M Dawood \\ National Research Center \\ Hassan Abd EL-Hafeth Rashed \\ Al-Azhar University Faculty of Medicine \\ Yasser M El-Dessouky \\ Al-Azhar University Faculty of Medicine \\ Galal AbdElhameed AbuFarrag \\ Al-Azhar University Faculty of Medicine \\ Islam Abdelmawla Ammar \\ Al-Azhar University Faculty of Medicine \\ Mohamed Mahmoud Abdel-Halim Mahmoud \\ Al-Azhar University Faculty of Medicine \\ Ghada M Salum \\ National Research Center for Genetic Engineering and Biotechnology: National Institute for Genetic Engineering and \\ Biotechnology \\ Mohamed Zakaria Abu-Amer \\ Al-Azhar University Faculty of Medicine \\ Mohamed Abd elrafaa Hassan Sekeen Sekeen \\ Al-Azhar University Faculty of Medicine \\ Mohamed Mousa Ibraheem Heggazy \\ Al-Azhar University Faculty of Medicine \\ Ahmed Mohamed Abdulhamid Altanbouly \\ Al-Azhar University Faculty of Medicine \\ Mai A El Meguid \\ National Research Center \\ Mostafa Kamel El Awady \\ National Research Center
}

\section{Research Article}

Keywords: IL28B-gene-SNPs, DAAs, PBMCs-PCR, HCV-Relapse

Posted Date: November 17th, 2021

DOI: https://doi.org/10.21203/rs.3.rs-1023473/v1 
License: (c) (i) This work is licensed under a Creative Commons Attribution 4.0 International License. Read Full License 


\section{Abstract}

Background and objective. IL28B-gene polymorphisms show inconclusive relationships with CHCV DAAs-treatment outcomes on evaluation by serum-PCR. Solitary intra-PBMCs HCV-RNA antisense-strands are independently found in naïve and experienced cases regardless to viremia or hepatic-parenchymal changes. We correlated frequencies of IL28B-gene SNPs and alleles with HCV induced liver-changes during SVR evaluation by PBMCs-PCR after DAAs-therapy.

Methods. Twelve weeks after completing DAAs-therapy, the impacts of IL28B-gene-SNPs were evaluated in three groups of patients: group- $I(n=25)$ with negative serum and PBMCs HCV-PCR, group- $I I(n=52)$ had solitary intra-PBMCs HCV-RNA, and group-III $(n=25)$ had positive serum HCV-RNA. All cases were subjected to IL28B-gene-SNP analyses and correlated with their ultrasonographic liver changes.

Results. IL28B-genotyping in post-DAAs-treatment HCV-SVR and viral relapse revealed: a) dominant CC-genotype and C allele in normal hepatic parenchyma in group-I compared to group-II $(P=0.0047,0.0007)$ and group-III $(P=0.0564,0.000003)$ b) frequent CT-SNP and T-allele in bright hepatic parenchyma in group-II when compared with group-I $(P=0.0077,0.002)$ and group-III $(P=0.0363,0.0005)$ c) increased TT-SNP and T-allele frequencies in coarse liver in group-III compared to groupI $(P=0.02256,0.000130)$ and group-II $(P=0.08647,0.004308)$.

Conclusions: Outcomes of HCV treatment with DAAs are dependent on host IL28B-gene polymorphisms and HCV induced liver changes. SVR is achieved when wild type-CC-genotype and C-allele are dominant in normal hepatic parenchyma; solitary intra-PBMCs-relapse occurs in increased frequency of CT-genotype when liver tissues are fibrotic; serologic-relapse is dominant when TT-genotype and T-allele are frequent in cirrhotic liver. IL28B-gene SNP analyses in relation to hepatic parenchymal changes are recommended before treating CHCV-infection with DAAs.

\section{Introduction}

Hepatitis $\mathrm{C}$ virus (HCV) infection causes chronic liver disease in almost 71 million individuals worldwide [1]. The highest prevalence of active HCV genotype 4 (G4) infection (10\%) is found among Egyptians, including the non-viremic anti-HCV IgG antibody seropositive and occult viral infections [2,3]. Introduction of first and second generation direct-acting antiviral therapies (DAAs) [4-9] improved HCV treatment outcomes with oral therapy and provided considerable advantage in evaluating host-related factors that may affect HCV-induced hepatic damage and response to medications $[10,11]$.

Analysis of IL28B-gene polymorphism in chronic HCV (CHCV) infection with hepatic parenchymal changes in worldwide populations has been described. Positive association of the IL28B-gene T allele was demonstrated in cirrhotic patients with HCV genotype 1 (G1) infection in Caucasian population. However, IL28B-gene SNP analyses in limited number of populations from Asia, Latin America or the Middle East who presented with $\mathrm{CHCV}$-induced hepatic parenchymal changes were inconclusive [12-15]. Additionally, the CT SNP of IL28B-gene was mainly reported in CHCV patients with liver cirrhosis followed by the TT SNP, while the wild type CC genotype was the least frequent in patients with cirrhosis [16]. Conversely, the role of IL28B-gene polymorphisms in liver cirrhosis was disputed by other investigators [17-19].

The CC genotype of IL28B-gene was reported in spontaneous clearance of HCV infection and was addressed as a favorable responder to the interferon (INF)-based therapy [20-22], while others reported association of the same CC genotype with higher prevalence of hepatic cirrhosis $[23,24]$ and elevated serum markers of necro-inflammatory hepatic responses $[15,17$, $19,23,24]$. The primary immune response to $\mathrm{CHCV}$ infection is mediated through IFN- $\lambda$ cytokines and may be influenced by IL28B-genotype $[25,26]$. There may be an association between IL28B-gene T allele and developing hepatocellular carcinoma (HCC) [27].

In 2019, Khan et al [28] reported association between IL28B-gene TT SNP and HCV post-DAAs treatment relapse/ resistance and between wild type CC of IL28B-gene and sustained viral response (SVR). In the same year, other researchers found that 
post-DAAs SVR was seen more often in wild C than T allele of IL28B-gene [29]. The high cure rate (up to 98\%) reported with DAAs in many studies is mainly based on clearance of the virus only from serum, but not from PBMCs. Contrarily, other investigators reported that more than $60 \%$ of the studied populations had positive HCV-RNA in PBMCs at the end of the $12^{\text {th }}$ week after treatment of CHCV infection with DAAs [30,31,32]. Disparity between serum and PBMCs PCRs in calculating SVR after DAAs therapy should promote continued IL28B-gene analysis, despite previous discrepant results of its association with treatment outcomes [33].

The current research aims to shed light on IL28B-genotyping variations in the response to DAAs treatment in the following situations: a) SVR with negative HCV RNA in serum and PBMCs, b) solitary intra-PBMCs HCV viral infection with negative serum viral PCR, c) positive HCV- RNA by serum PCR. The IL28B-gene polymorphisms in association with DAAs treatment outcomes were correlated with ultrasound (US) grading of CHCV-induced hepatic parenchymal changes.

\section{Subjects And Methods}

I. Subjects: Patients were recruited from the outpatient clinic of hepatology, gastroenterology, and infectious diseases at AlAzhar university specialized hospital. Twelve weeks after end of treatment (EOT) with DAAs, 102 subjects were randomly selected as demonstrated below by the flow chart in figure 1 .

The 102 selected subjects were screened by both serum and PBMCs HCV SRT-PCR, and then divided into three groups: I $(n=25)$ with negative HCV RNA in serum and PBMCs, II $(n=52)$ had negative serum HCV RNA but positive viral RNA in PBMCs, and III $(n=25)$ had still positive HCV RNA in serum. The studied groups were matching regarding age, gender, and treatment regimen. Age range of the selected subjects was between 18 and 75 years. The exclusion criteria included coinfection with HIV or HBV, pregnant female, hepatocellular carcinoma, total serum bilirubin more than $3 \mathrm{mg} / \mathrm{dl}$, INR more than 1.7, serum albumin less than $2.8 \mathrm{~g} / \mathrm{dl}$ and platelet count less than $50,000 / \mathrm{mm}$. All study subjects were treated with DAAs (400mg SOF +60mg DCV) \pm RBV (up to $1200 \mathrm{mg}$ according to body weight) for 12 weeks according to national guidelines for HCV management in Egypt as described above in figure 1.

II. SVR assessment by SRT-PCR for detection of HCV-RNA: Undetectable serum HCV-RNA was checked 12 weeks after the end of SOF/DCV \pm RBV treatment. Firstly, HCV-RNA was extracted from serum by using QIAamp Viral RNA Mini Kit (Qiagen artus, Hildenm, German). Total cellular RNA was extracted from the isolated PBMCs using the single-step method that was first published by Chomczynski and Sacchi [34] and modified later [3, 35, 36, 37] to detect HCV-RNA in PBMCs. Nested SRTPCR was performed as confirmatory test by using $25 \mu \mathrm{L}$ reaction mixture as described before [38].

III- IL28B gene polymorphism Screening: The SNPs of IL28B gene were identified using a real-time PCR protocol based on the pre-validated TaqMan MGB ${ }^{\text {TM }}$ probe for allelic discrimination assay (Applied Biosystems, Foster City, California, US). Briefly, $1.25 \mu \mathrm{L}$ of a $40 \mathrm{X}$ combined primer and probe mix (ABI/Life Technologies, USA) was added to $12.5 \mu \mathrm{L}$ of $2 \mathrm{X}$ TaqMan® Universal PCR master mix (ABI/Life technologies, USA) in a $25 \mu L$ final volume of DNAse / RNAse-free water (Invitrogen/Life Technologies, USA) and template. The cycling conditions were: $95^{\circ} \mathrm{C}$ for $10 \mathrm{~min}, 95^{\circ} \mathrm{C}$ for $15 \mathrm{~s}$, and $60{ }^{\circ} \mathrm{C}$ for $1 \mathrm{~min}$. The last two steps were repeated 40 times. The PCR run was performed on Rotor Gene real-time PCR system (Qiagen, Santa Clarita, CA). Allelic discrimination plots were produced in Statistical Package for The Social Sciences (SPSS version 16.0; SPSS, Chicago, IL).

IV. Evaluation of hepatic parenchymal changes (early fibrosis and late cirrhosis): CHCV induced liver tissue changes were examined by ultrasonography (US) images and were correlated with Fib4 scoring system in all study subjects. US images were classified into undetectable, early, and cirrhotic hepatic changes. These three categories were correlated with the corresponding values of Fib4 score. Ultrasound is a convenient descent screening tool for hepatic cirrhosis and its complications. In the current research, real time ultrasound using 3.5-5.0 MHz convex transducer by the radiologist on duty in the ultrasound interventional suit having at least 5 years of experience in performing abdominal sonography. Ultrasound of liver lobes and spleen were performed, and a combined impression was derived. Sizes of liver, spleen, and portal vein 
were also assessed. The elaborated description of cirrhotic findings on US examination included: a) surface nodularity (88\% sensitive, 82-95\% specific) b) overall coarse and heterogeneous echotexture c) segmental hypertrophy/atrophy d) caudate width to right lobe width $>0.65$ (43-84\% sensitive, 100\% specific) e) reduction of the transverse diameter ( $<30 \mathrm{~mm})$ of the medial segment of hepatic left lobe (segment). Portal hypertension was addressed by detecting the enlarged portal vein: $>13 \mathrm{~mm}$ (42\% sensitive, $95-100 \%$ specific).

V. Statistics: SPSS 16.0 (IBM; NY, USA) was used to analyze the current data set. Results were presented as compared with the $\mathrm{X}^{2}$ or Fisher exact tests; continuous variables were expressed in term of means and standard deviations, while ordinal and nominal categorical results were addressed as number and percentage. Categorical variables were appropriate, and the effect of differences was established by calculating the odds ratio with the $95 \%$ confidence interval $(95 \% \mathrm{Cl})$. According to variable distribution, 1-way ANOVA or nonparametric Kruskal-Wallis test was used for multi-group comparisons. $P<0.05$ indicated significant difference.

\section{Results}

\section{The demographic data of the Studied groups}

Variations in both demographic and clinical data were limited because of the invented study protocol instructions, as cases were selected according to the national guidelines for chronic HCV management. The included subjects were characterized by absent ascites; insignificant variation in organomegaly; normal ranges of serum creatinine, liver enzymes, serum bilirubin \& albumen, INR, and alpha fetoprotein; insignificant difference in the CBC ingredient ranges; no active hematemesis or recent esophageal varices ligation; no major cardiovascular problem; no malignancy or immunocompromised disorders; no pregnancy for females. Regarding variations in age and gender, no significant difference was found among the three studied groups ( $P=0.443$ for age and 0.711 for gender), despite the predominance of male gender within each group when compared to female $(P<0.001)$. History of contact with canal water was not checked out and subsequently Schistosomiasis coinfection was not evaluated. These two errors (gender distribution within each group and exclusion of Schistosomiasis coinfection) might influence the current research outcomes and should be considered in the fore coming studies, as their justification would help in both data analysis and interpretation.

\section{Relationship between DAAs therapeutic regimen and relapse category in the studied populations.}

The distribution of both dual (SOF and DCV) and triple (SOF and DCV plus RBV) regimens in the studied populations $(n=102)$ was illustrated in figure 2 . Subjects who received dual regimen $(n=60)$ were respectively presented in group I, II, and III as $16.67 \%(n=10), 60 \%(n=36)$ and $23.33 \%(n=14)$ as described in figure 2 A. The received triple regimen by 42 patients was administered in $35.71 \%(n=15), 38.09(n=16)$, and $26.19 \%(n=11)$ of groups I, II, and III respectively as shown in figure 2B. Analysis of the afro-mentioned results revealed that, high dual therapy intake was reported in group II compared to group I $(P<0.00001)$ and group III $(P<0.0001)$, while triple regimen administration had the same rates in the three groups $(P>0.3)$. Within each group, there was increased triple regimen intake in group I $(P=0.035973)$ and dual regimen administration in group II ( $P=0.043738)$, while group III showed insignificant difference between the two regimens $(P=1.000000)$. Accordingly, dual therapy seems to be strongly associated with increased frequency of cellular relapses.

\section{Evaluation of HCV replication during relapse via detecting intra-PBMCs antisense RNA-strand.}

The distribution of sense and anti-sense RNA strands within PBMCs of relapsers after DAAs therapy in groups II and III was described in figure 3. Groups II and III showed intra-PBMCs HCV-RNA sense and antisense strands in 41 out of 52 (78\%) and in 14 out of $25(56 \%)$ respectively, while solitary antisense RNA-strands were detected in 4 out of $52(7.69 \%)$ and in 5 out of $25(20 \%)$ of groups II and III respectively. The total numbers of relapsers who had actively replicating intracellular viral genomes were 45 out of 52 in group II and 19 out of 25 in group III, while the rest of relapsers had HCV-RNA sensestrands that were found in 7 out of $52(13.46 \%)$ and in 6 of 25 (24\%) of groups II and III respectively. Figure (3) 
demonstrated that association of HCV replication due to presence of HCV-RNA antisense strand inside PBMCs was more frequent than solitary sense strands; a finding that reflected significant viral replication in group II $(P<0.0001)$ and group III $(\mathrm{P}<0.0005)$.

\section{Correlation of IL28B-gene SNPs with US hepatic parenchymal changes.}

Correlation of IL-28 gene SNPs with US liver changes of all study groups was illustrated in table 1. Variations of IL-28 gene SNPs in normal hepatic US appearance indicated the following: a) higher frequency of wild type CC in post-DAAs treatment in group I compared to solitary intracellular infection (group II) ( $\mathrm{P}=0.0047)$ and serum HCV-RNA still positive patients (group III) $(P=0.0564)$ b) CT-genotype was seen more often during solitary intra-PBMCs HCV viral infection in Group II and in SVR subjects (group I) compared with serum HCV-RNA still positive patients in group III ( $P=0.0008$ and 0.024 , respectively); with insignificant changes when comparing groups I with II $(\mathrm{p}=0.3844) c$ ) no significant difference in TT genotype was observed on comparing the three groups with each other ( $\mathrm{P}>0.4)$. In bright liver (early parenchymal changes) by ultrasound, the obtained data in table (1) revealed that: a) CT-genotype was seen more often in solely intracellular HCV infection (Group II) than in SVR subjects (group I) (P=0.0077) and group III patients who retained detectable serum RNA by PCR $(\mathrm{P}=0.0363) \boldsymbol{b}$ ) both wild type CC and TT-genotype were almost equally distributed in the three groups. In patient with coarse liver by ultrasound current findings indicated the following: a) TT-genotype was seen more often in group III (positive serum HCV-RNA) than group I (negative serum and cellular PCRs) $(P=0.0434)$ and group II (only cellular HCV-RNA) $(\mathrm{P}=0.1719)$ b) no significant differences were seen in both wild type CC and CT-genotype when comparing the three groups with each other $(P>0.1)$.

On comparing the sum of IL-28 gene SNP variation in all study groups within each US category regardless to infection status, the following findings were noted :- $\boldsymbol{A}$ ) in normal US hepatic appearance. both wild type CC (12 out of 31) and CT genotype (16 out of 31) were more frequent than TT-genotype (3 out of 31) ( $P=0.015878$, and 0.000692, respectively); with insignificant difference when comparing the wild type CC to the CT-genotype $(P=0.444257)$. B) in bright hepatic parenchymal tissues by US. the CT-genotype (29 out of 55) was seen more often than wild type CC (9 out of 55) and TTgenotype (17 out of 55) ( $\mathrm{P}=0.000109$, and 0.03296 , respectively); with no difference on comparing the wild type CC with TT-genotype $(\mathrm{P}=0.1152)$. C) in Coarse liver parenchyma by US. frequencies of the wild type CC (5 out of 16), CT (5 out of 16 ) and TT (6 out of 16) genotypes showed insignificant differences $(P=1.0000)$.

The frequency of CT-genotype in chronic HCV infected patients (50 out of 102) regardless of post-treatment virologic status was significantly higher than the wild type CC (26 out of 102) and the mutated TT genotype (26 out of 102) (P=0.0008). This finding reflected the following $\boldsymbol{a}$. an increased susceptibility to develop chronic HCV infection $\boldsymbol{b}$. an increased resistance to DAAs therapy $\boldsymbol{c}$. higher probability of persistent HCV RNA in PBMCs, in CT genotype ( $\mathrm{n}=29)$ when compared to serologic relapses $(n=5)$ and SVR $(n=16)$ among a total of 50 intracellular HCV infections, $P<0.05$.

Table 1. Single nucleotide polymorphism (SNPS) of IL28 gene in relation to hepatic ultrasound (US) image variations 


\begin{tabular}{|c|c|c|c|c|c|c|c|c|c|}
\hline \multirow[b]{2}{*}{$\begin{array}{l}\text { Study } \\
\text { groups }\end{array}$} & \multicolumn{3}{|c|}{ Normal liver by US $(n=31)$} & \multicolumn{3}{|c|}{ Bright liver by US ( $n=55)$} & \multicolumn{3}{|c|}{ Cirrhotic liver by US $(n=16)$} \\
\hline & $\mathrm{CC}$ & CT & TT & $\mathrm{CC}$ & CT & TT & $\mathrm{CC}$ & CT & TT \\
\hline Group & $8(25.8 \%)$ & $6(19.3 \%)$ & $1(3.2 \%)$ & $0(0 \%)$ & $5(9 \%)$ & $5(9 \%)$ & $0(0 \%)$ & $0(0 \%)$ & $0(0 \%)$ \\
\hline $\begin{array}{l}\text { Group } \\
\text { II }\end{array}$ & $4(12.9 \%)$ & $10(32.2 \%)$ & $2(6.4 \%)$ & $4(7.2 \%)$ & $17(30.9 \%)$ & $9(16.3 \%)$ & $4(25 \%)$ & $\begin{array}{l}1 \\
(6.2 \%)\end{array}$ & $1(6.2 \%)$ \\
\hline $\begin{array}{l}\text { Group } \\
\text { III }\end{array}$ & $0(0 \%)$ & $0(0 \%)$ & $0(0 \%)$ & $5(9 \%)$ & $7(12.7 \%)$ & $3(5.4 \%)$ & $\begin{array}{l}1 \\
(6.2 \%)\end{array}$ & $4(25 \%)$ & $5(31.2 \%)$ \\
\hline P & 0.1102 & 0.3844 & 1.0000 & 0.1181 & 0.0077 & 0.3916 & 0.1012 & 1.0000 & 1.0000 \\
\hline | vs || & 0.0047 & 0.0240 & 10000 & 0.0568 & 0.7611 & 0.7161 & 1.0000 & 0.3325 & 0.0434 \\
\hline III vs & 0.0564 & 0.0008 & 0.4918 & 1.0000 & 0.0363 & 0.1235 & 0.3326 & 0.1012 & 0.1719 \\
\hline III $^{\text {II vs }}$ & & & & & & & & & \\
\hline
\end{tabular}

In patients with normal hepatic ultrasound: a) frequency of wild type CC was higher in group I compared to group II $(P=0.0047)$ and group III ( $P=0.0564)$ b) CT-genotype was seen more often during solely intracellular HCV infection in group II compared to RNA-seropositive patients in group III ( $\mathrm{P}=0.0008)$. In patients with bright liver by ultrasound: a) CT-genotype was more frequent in solitary intracellular Infection (group II) than in SVR subjects (group I, P=0.0077) or those with positive serum RNA by PCR (group III, $\mathrm{P}=0.0363$ ) b) both wild type CC and TT-genotype were almost equally distributed in the three groups. In cases with coarse liver by US image: a) TT-genotype was found more often in group III (positive serum HCV-PCR) compared to group I $(P=0.0434)$ and group II $(P=0.1719)$ b) no significant difference was observed in both wild type CC and CT-genotype on comparing the three groups to each other. Fisher exact 2 tailed $\mathrm{P}$ was used in data analysis.

The algorism presented in figure 4 summarized frequencies of the wild type CC, as well as CT and TT genotypes respectively in SVR, solitary PBMCs and serum HCV relapses in relation to hepatic parenchymal changes after DAAs therapy. Data presented in the figure concluded that the wild type CC were associated with full response to DAAs therapy when changes in liver tissues were not detected by US. The CT genotype was recognized in cases with HCV-PBMCs relapse predominantly in those who developed bright liver image (early stages of liver cirrhosis) by US. The mutant genotype (TT) was mainly observed with serologic HCV relapse, particularly in those who presented with liver cirrhosis. These data proposed that host genetics (IL28 B genotypes) contributed a major role in determining the pathophysiologic effects of $\mathrm{CHCV}$ infection on liver tissues and subsequently on the response to DAAs therapy.

\section{Correlation of IL28B-allele frequencies with the evaluated liver tissue changes by Ultrasound (US)}

The relationship of $\mathrm{C}$ or T allele frequency with various US images of hepatic parenchyma in the studied CHCV cohort was illustrated in table 2. When no abnormality detected (NAD) by US image ( $\mathrm{n}=62$ allele) was addressed, the C allele of IL28gene was recognized more often in both SVR (group I) and cellular relapse (group II) compared to serologic relapse in group III $(\mathrm{P}<0.0001)$, while T allele was frequently recognized more in group II compared with group I ( $\mathrm{P}=0.0061)$ and III $(P<0.0001)$. When liver tissues appear bright in early hepatic parenchymal changes by US ( $n=110$ allele), the T allele was more recognizable in group II than SVR patients in group I $(\mathrm{P}=0.002)$ and HCV-RNA seropositive patients in group III $(P=0.0005)$. In coarse hepatic parenchyma by US ( $n=32$ allele), the T allele was more frequently seen in group III compared to SVR in group I (SVR) $(P<0.0001)$ and cellular relapsers in group II $(P<0.0001)$. On the other hand, the $C$ allele was 
recognized more often in cellular relapse when liver parenchyma was bright $(P=0.0001)$ or cirrhotic $(P=0.002)$ on comparison with sustained virologic responders who had bright and cirrhotic liver respectively.

Comparing frequency of $\mathrm{C}$ or T allele within each group with correlation to US image categories revealed the following: - a) the SVR group had significantly higher frequency of $\mathrm{C}$ allele when US showed no abnormality (22 out of 62) compared to bright (5 out of 110) $(\mathrm{P}=0.00000019)$ or cirrhotic liver tissues (0 out of 32) ( $\mathrm{P}=0.0000242)$ b) cellular relapse in group II had more T allele in bright liver (35 out of 110) compared to normally appearing US image (14 out of 62) ( $P=0.221681)$, and coarse liver (3 out of 32) ( $\mathrm{P}=0.01206814)$ c) serologic relapse in group III showed significantly higher frequency of $\mathrm{T}$ allele in cirrhotic (14 out of 32) compared to normally appearing (0 out of 62) ( $P=0.00000003$ ), and bright hepatic parenchyma (13 out of 110) $(P=0.00226992)$. Fisher exact 2 tailed $P$ was used to analyze data.

Table 2. Correlation of IL28B-gene alleles (T or C) with grads of hepatic parenchyma by Ultrasound (US) in post-DAAs therapy outcomes

\begin{tabular}{|c|c|c|c|c|c|c|}
\hline \multirow[b]{2}{*}{ Study groups } & \multicolumn{2}{|c|}{ Normal liver by US $(n=62)$} & \multicolumn{2}{|c|}{ Bright liver by US ( $n=110)$} & \multicolumn{2}{|c|}{ Coarse liver by US $(n=32)$} \\
\hline & C allele & T allele & C allele & T allele & C allele & T allele \\
\hline Group I & $22(35.4 \%)$ & $8(12.9 \%)$ & $5(4.5 \%)$ & $15(13.6 \%)$ & $0(0 \%)$ & $0(0 \%)$ \\
\hline Group II & $18(29 \%)$ & $14(22.5 \%)$ & $25(22.7 \%)$ & 35 (31.8\%) & $9(28.1 \%)$ & $3(9.3 \%)$ \\
\hline Group III & $0(0 \%)$ & $0(0 \%)$ & $17(15.4 \%)$ & $13(11.8 \%)$ & $6(18.7 \%)$ & $14(43.7 \%)$ \\
\hline P Value: I vs II & 0.5647 & 0.2395 & 0.0001 & 0.0020 & 0.0020 & 0.2381 \\
\hline I vs III & $<0.0001$ & 0.0061 & 0.0119 & 0.8401 & 0.0242 & $<0.0001$ \\
\hline II vs III & $<0.0001$ & $<0.0001$ & 0.2296 & 0.0005 & 0.5561 & 0.0038 \\
\hline
\end{tabular}

In normally liver tissues by US, C allele was more frequent in both group I and II compared to group III $(\mathrm{P}<0.0001)$, while T allele was significantly recognized in group II compared to group I $(\mathrm{P}=0.0061)$ and III $(\mathrm{P}<0.0001)$. In bright liver tissue $(\underline{\text { early }}$ hepatic parenchymal changes) by image, the T allele was associated with intracellular HCV infection (group II) when compared to SVR in group I $(\mathrm{P}=0.002)$ and serologic viral relapse in group III $(\mathrm{P}=0.0005)$. In cirrhotic liver by sonographic examination the T allele was more frequent in HCV RNA seroconversion (group III) compared to SVR in group I ( $<<0.0001)$ and cellular relapse in group II $(\mathrm{P}<0.0001)$. The $\mathrm{C}$ allele showed higher association with cellular HCV relapse in bright $(P=0.0001)$ and cirrhotic $(P=0.002)$ liver respectively when compared to SVR in bright and cirrhotic liver parenchymal changes.

Distribution of $\mathrm{C}$ and $\mathrm{T}$ alleles of IL28B-gene was evaluated in the recruited three post-DAAs therapy groups, as described in Figure 5. The studied population were classified according to the ultrasonographic appearance of hepatic tissues into three categories: a) no abnormality detected (NAD) b) early hepatic parenchymal changes defined as bright liver c) coarse liver surface defined as hepatic cirrhosis. The algorism in figure 5 showed that: a) SVR and PBMCs-relapse were respectively associated with $\mathrm{C}$ and $\mathrm{T}$ alleles when hepatic US had NAD category $b$ ) PBMCs relapse was associated with $\mathrm{C}$ or $\mathrm{T}$ allele when liver US showed bright category during early hepatic parenchymal changes $c$ ) serum and PBMCs HCV relapses were respectively associated with $\mathrm{T}$ and $\mathrm{C}$ alleles when hepatic US had the coarse category.

\section{Discussion}

Molecular structure of cytokine genes has become a valuable screening tool that may explain variations in the outcomes of treatment in chronic infectious diseases like HCV infection. The interleukin-28B (IL28B) gene is found with IL28A and IL29 in a cytokine cluster at 19q13.13 and codes for IFN $\lambda 3$. The upstream haplotype associated with viral clearance at SNPs rs12979860 and rs8099917 is CT, and the persistence haplotype at these SNPs is TG. IL28B-gene polymorphism showed 
SNP patterns that are clearly associated with distinct post Peg-INF treatment outcomes [20-24]. Introduction of DAAs in 2014 , raised more debate regarding effectiveness because of the variation in therapeutic outcomes. The role of IL28B-gene polymorphism in DAAs treatment outcomes remains under investigation due to worldwide variations in viral relapse/ breakthrough rates [28-32].

CHCV infection induces liver pathology ranging from hepatic stiffness and fibrosis to liver cirrhosis [39]. Liver cirrhosis caused by CHCV infection may occur in association with certain SNPs of some known and mostly unknown host genes, which may additionally predispose to viral relapses. The fact that $\mathrm{CHCV}$ infection causes liver cirrhosis in a small fraction of the affected population further illustrates whether specific host factors are at play. Screening for HCV cellular relapse by PBMCs-PCR suggests incomplete evaluation of SVR by serum HCV-PCR alone [30,31, 32]. Therefore, further research is needed to study the relationship between gene SNPs and occurrence of various grades of hepatic parenchymal changes before proposing the antiviral therapeutic regimens.

HCV RNA detection in serum is used to determine post-DAAs response; either as SVR, no response or relapse. SVR is assessed at the end of the $12^{\text {th }}$ week after end of treatment (EOT) when serum HCV-PCR turns negative [4-9]. When adding PBMCs-PCR to HCV diagnostic protocol, other researchers suggested different definitions of nonresponse, relapse, and SVR given the persistent detection of intracellular HCV-RNA genomic strands [34, 38]. It has also been reported that follow-up of both naïve and experienced patients with solitary positive intra-PBMCs HCV infection was associated with viral-RNA seroconversion [3]. Subjects presented with SVR had negative serum and PBMCs HCV by PCR, while those with serologic relapse had positive serum viral-RNA PCR after 12 weeks from EOT. The current research used a third group of patients who had solitary intra-PBMCs HCV-RNA at the end of the $12^{\text {th }}$ week after EOT, with antisense and / or sense RNA-strands as a sign of active viral replication and given the definition of cellular relapsers as documented previously by other investigators [30-32].

The overall clinical significances of intracellular HCV-RNA detection within nucleated blood cells of CHCV patients may be addressed during evaluation of diagnosis, prognosis, antiviral regimens administration, viral treatment outcome, and extrahepatic tissue viral tropism. For treating CHCV infection, positive serum viral-RNA PCR is an absolute requirement. The persistence of intra-PBMCs HCV-RNA antisense (replicative) and / or sense (antigenic) strands have been demonstrated in $100 \%$ of HCV-RNA viremic patients who presented with positive serum-PCR regardless to viral load [32, 40]. SVR after antiHCV therapy is achieved when both serum and PBMCs show negative HCV-RNA by PCR, as posttreatment persistence of intracellular viral genomic materials is associated with increased probability of serologic viral relapses [36,37]. Application of HCV treatment follow-up fractionation (CTF2) protocol, which is based on HCV-RNA recognition in serum and in PBMCs at two weeks intervals, coordinates anti-viral therapy termination (after 2 to $>24$ weeks) with accomplishing SVR (negative serum and cellular HCV-PCR) during using any proposed antiviral regimen. At the end of HCV therapy, the applied CTF2 protocol differentiates responders from non-responders in addition to addressing HCV relapse possibility [41]. Diagnostic and prognostic evaluation of both cryptogenic and occult HCV infection (OCI) have been clinical challenges. These two entities are partially solved by screening PBMCs for intracellular HCV-RNA [36]. In addition, progressing liver cirrhosis to HCC is seen more often after DAAs therapy in association with solitary persistence of HCV-RNA within PBMCs [37]. Application of the same procedure (mononuclear cells HCV-PCR) to detect viral-RNA antisense and sense strands within bone marrow mononuclear cells (BMMCs) proved that bone marrow (BM) tissues are primary sites for viral replication (HCV Bone Marrow tropism), as HCV-RNA viremia occurs only when BM-tissues are active (functioning). In BM failure with negative BMMC HCV PCR, positive PBMCs for viral-genomic materials may reflect activities of extra bone marrow hematopoietic tissues in viral-RNA seronegative CHCV infection. BMMCs HCV-RNA PCR screening of OCl adds $>12 \%$ extra newly diagnosed hidden viral infection only when BM-tissues are active (unpublished data).

Variations in abdominal ultrasound (US) screening results that may occur because of differences among experienced hands (hand bias) during solid organs evaluation are limited. The US screening of liver tissues in the current research was performed using a real time 3.5-5.0 $\mathrm{MHz}$ convex transducer by radiologists who have at least 5 years of experience in 
performing sonography at the intervention radiology suit. So, hand bias would have a minimum influence on generating the same data sets by different radiologists who have long-term expertise. Although liver tissues sonography may not be enough to evaluate hepatic parenchymal changes, the US would be conclusive in addressing the following clinical presentations: a) no abnormality detected when liver tissues appear normal $\boldsymbol{b}$ ) cirrhotic liver by recognizing coarse hepatic surface. The third clinical category is bright liver that requires differentiation between early CHCV-induced hepatic parenchymal changes and other liver pathology (e.g., fatty liver). In our research, almost all cases who presented with bright liver were normotensive, nondiabetic, had average BMI, normal liver enzymes \& lipid profile, positive anti-HCV IgG antibody serology, and had or still having positive serum HCV-RNA PCR. The above-mentioned US criticism (hand bias) was managed by adding Fib4 scoring system in comparison to hepatic imaging by US to evaluate their compatibility and to validate US use in the current research as demonstrated previously [32].

The current study shows considerable correlation between IL28B-gene variants and treatment outcomes 12 weeks post EOT with DAAs. The selected 102 subjects constituted 3 groups of CHCV patients with different post-DAAs treatment outcomes. All three groups were screened by US for hepatic parenchymal changes and IL $28 \mathrm{~B}$ gene polymorphism. A relationship between the IL28B-gene variants with both HCV relapse and liver parenchymal changes was addressed. In patients who had normal liver parenchyma, we describe high frequencies of the wild type CC in the SVR group, and CT genotype in persistent intra-PBMCs HCV-RNA group. On the other hand, TT-genotype of the IL28-gene were seen more often in cases of HCV serologic relapse when patients had cirrhotic liver. An additional arm of assaying HCV-RNA in PBMCs has significantly changed observations made by other studies regarding whether IL28B-gene SNPs exhibited either positive [12-17] or negative [18] correlations with anti-HCV DAAs treatment outcomes.

The association between IL28B genotyping with PBMCs HCV relapse in different grades of liver parenchymal changes was addressed for the first time in the current study. In bright liver by US (i.e., early changes), cellular relapse occurs frequently regardless of IL28B-gene makeup. However, the presence of $\mathrm{C}$ allele seems to ameliorate CHCV infection and to improve DAAs therapy outcomes. At this point we can then conclude that: a) dominance of $\mathrm{C}$ allele in normal liver parenchyma by US is associated with clearance of both serum and cellular HCV infection (SVR) $\boldsymbol{b}$ ) recognition of C allele dominance in bright (early fibrotic) or coarse (cirrhotic) liver leads to clearance of viremia despite persistence of PBMCs HCV-RNA. Contrarily, dominance of T allele seems to be an unfavorable association as it leads to worse HCV infection outcomes and increase in viral relapse after DAAs therapy. Therefore the other facet of the picture will be: a) dominant T allele is associated with HCV serologic relapse in cirrhotic liver with coarse surface by US b) frequent recognition of $\mathrm{T}$ allele in normal and bright hepatic tissues by US is accompanied by persistent intra-PBMCs HCV infection despite serum viral-RNA clearance.

The disparity between serum and PBMCs HCV-PCRs in SVR calculation after DAAs therapy may encourage researchers to continue IL28B-genotype assay, despite calls discouraging this practice [33]. Clinical application of these results will help to predict treatment outcomes when using current DAAs regimens before their administration in CHCV patients. Pretreatment identification of the IL28B genotyping in relation to liver parenchymal changes before starting DAAs therapy of CHCV infection could predict one of the following: $a$. high likelihood of full clearance of the HCV from serum and tissues in wild type $\mathrm{CC}$ or $\mathrm{C}$ allele predominance in those with normal liver parenchyma $\boldsymbol{b}$. likelihood of solitary intra-PBMCs HCV RNA in IL28B CT heterozygotes when liver is fibrotic (bright by US), during increased frequency of $C$ allele when liver is cirrhotic (coarse surface by US), and on dominance of T allele when liver tissues appear normal (no abnormality detected by US) $\boldsymbol{c}$. risk of serologic relapse on predominance of IL28B TT genotype or high frequency of T allele in established liver cirrhosis (coarse surface by US). Further studies are needed to address the relationship between the IL28B-gene SNPs and DAAs regimens and new antiviral therapies, other than the currently used therapeutic regimens, that have been described in other HCV management protocols $[4,6,7]$, and drug administration for either extended or shortened durations as compared to current or previous studies [41]. 
Pretreatment submission of CHCV-patients to IL28B-gene typing in relation to hepatic parenchymal changes elaborates one of the following clinically applied outcomes: $\underline{a}$. SVR in wild CC genotype when liver tissues look normal by US, which might favor feasibility to reduce duration of the antiviral treatment course $\underline{b}$. Solitary intra-PBMCs persistence of HCV-RNA in wild CC and CT heterozygotes when liver tissues are fibrotic (bright liver by US), a situation that might require extension of DAAs course duration beyond the scheduled termination point until elimination of intracellular viral RNA $\underline{c}$. Serologic viral relapse (positive serum HVC-PCR) in TT genotype when liver tissues are cirrhotic (coarse hepatic surface by US), a clinical presentation that requires either viral genome screening for RAS or adding Ribavirin to the currently used regimen or using different antiviral regimens for may be longer duration than the anticipated end point of treatment. In addition, predominance of IL28B-gene C or T allele in CHCV infection reveals one of the following situations: $\underline{d}$. SVR and PBMCs relapse are respectively seen in normal and cirrhotic liver tissues when $\mathrm{C}$ allele is dominant $\underline{\boldsymbol{e}}$. PBMCs and serologic relapses are respectively more frequent in normal (NAD by US) and cirrhotic hepatic parenchyma (coarse liver surface by US) on dominance of T allele $\underline{f}$. Cellular relapse is found more often in bright liver tissues by US (early hepatic parenchymal changes) on dominance of either $\mathrm{C}$ or $\mathrm{T}$ alleles.

\section{Conclusions}

IL28B-gene polymorphism shows considerable relationship with treatment outcomes in various virally - induced hepatic parenchymal changes. The wild type CC and higher $\mathrm{C}$ allele frequency were more likely in SVR cases particularly in normal hepatic parenchyma by ultrasound (US). The heterozygous IL28B CT were identified in solitary intra-PBMCS HCV relapse in cases with early fibrotic liver parenchyma (bright liver by US). $T$ and $C$ alleles were respectively associated with solitary PBMCs relapse in normal and cirrhotic liver. Finally, The TT-genotype and subsequently T allele frequency are dominant in HCV serologic relapse in association with liver cirrhosis (coarse surface by US). Pre-treatment screening of the IL28B-gene polymorphism (rs12979860) for large scale studies are needed to further confirm these findings in different therapeutic regimens and various grades of HCV-induced liver tissues changes. Despite clear disparity between serum and PBMCs PCRs in SVR calculation after DAAs therapy, the current study supports continued IL28B-genotype assay before CHCV treatment induction.

\section{Declarations}

Acknowledgements: Financial support for this study was provided by the Faculty of Medicine at Al-Azhar University and National Research Center (Cairo, Egypt).

Author contributions: The second and last two authors executed the virologic investigation and helped in writing the manuscript. The corresponding author took care of study design, cases managements, data analysis, and writing the manuscript; other co-authors helped in recruiting and management of patients and revised the manuscript.

Funding of this study came from Department of Hepatology, Gastroenterology, and Infectious Diseases; Faculty of Medicine at Al-Azhar University; Cairo, Egypt. The institutes have no conflict of interest.

Compliance with ethical standards: - a) Conflict of interest: The authors have no conflicts of interest related to this publication $\boldsymbol{b}$ ) Human and animal rights: All procedures performed in the current study that involved human participants were in accordance with the ethical standards of the institutional and/or national research committee and with the 1964 Helsinki declaration and its later amendments or comparable ethical standards c) Informed consent: Informed consent was obtained from all individual participants included in the current study. This article does not contain any studies with animals performed by any of the authors $d$ ) Ethical approval certificate Registration number: Trop.Med._13Med.Research_Inf.GIT.Liv.Dis._0000013.

\section{References}

Page $11 / 17$ 
1- Ministry of health and population (Egypt), El-Zanaty and associates (Egypt) and ICF international (2014) Egypt demographic and health survey. Egypt and Rockville, Maryland, USA.

2- European Association for the Study of the Liver (2018) EASL recommendations on treatment of hepatitis C. Journal of hepatology 69 (2): 461-511.

3- Abd Alla, MDA, \& El Awady MK (2017) Hepatitis C virus RNA strands detection in peripheral blood mononuclear cells legitimizes virus eradication in negative serum PCR naïve and post-treatment patients. J Clin \&Transl Hepatol 5:1-8.

4- Nelson DR, Roth D, Bruchfeld A, Liapaki A, Silv M, Monsour JH, et al (2015) Grazoprevir plus elbasvir in treatment-naive and treatment-experienced patients with hepatitis $C$ virus genotype 1 infection and stage $4-5$ chronic kidney disease (the CSURFER study): a combination phase 3 study. The Lancet 386 (10003): 1537-1545.

5- Charlton M, Everson GT, Flamm SL, Kumar P, Landis C, Brown Jr, et al (2015) Ledipasvir and sofosbuvir plus ribavirin for treatment of HCV infection in patients with advanced liver disease. Gastroenterology 149: 649-59.

6- Sterling RK, Kuo A, Rustgi VK, Sulkowski MS, Stewart TG, Fenkel JM, et al (2015) Virological outcomes and treatment algorithms utilisation in observational study of patients with chronic hepatitis $C$ treated with boceprevir or telaprevir. Alimentary pharmacology \& therapeutics 41(7): 671-685.

7- Ioannou GN, Beste LA, Chang MF, Green PK, Lowy E, Tsui Jl, et al (2016) Effectiveness of sofosbuvir, ledipasvir/sofosbuvir, or paritaprevir/ritonavir/ombitasvir and dasabuvir regimens for treatment of patients with hepatitis $\mathrm{C}$ in the Veterans Affairs National Health Care System. Gastroenterology 151(3): 457-471.

8- Abd Alla MDA, Gomaa AA, Farrag GAA, Shikhroho MG, Mousa WM, Mahmoud OA (2018) Retrospective study of hepatitis c virus relapse after treatment with sofosbuvir and daclatasvir with or without ribavirin. Al-Azhar Assiut Medical Journal 16 (2): 197-204.

9- Huang CF, Yeh ML, Huang Cl, Liang PC, Lin YH, Hsieh MY (2020) Huang JF. Ribavirin facilitates early viral kinetics in chronic hepatitis C patients receiving daclatasvir/asunaprevir. Journal of gastroenterology and hepatology 35 (1): 151-156.

10- Vasilios P, Stylianos K (2015) Current status and emerging challenges in the treatment of hepatitis C virus genotypes 4 to 6. World J Clin Cases 3(3): 210-220.

11- Coppola N, Pisaturo M, Sagnelli C, Onorato L, Sagnelli E (2015) Role of genetic polymorphisms in hepatitis C virus chronic infection. World Journal of Clinical Cases: WJCC 3 (9): 807-822.

12-Mangia A, De Ledinghen V, Bailly F, Brahm J, Keiss J, Valantinas J, et al (2016) IL28B genotype is associated with cirrhosis or transition to cirrhosis in treatment-naive patients with chronic HCV genotype 1 infection: the international observational Gen-C study. SpringerPlus 5 (1): 1-13.

13-Falleti E, Bitetto D, Fabris C, Cussigh A, Fornasiere E, Cmet S et al (2011) Role of interleukin 28B rs12979860 C/T polymorphism on the histological outcome of chronic hepatitis C: relationship with gender and viral genotype. J Clin Immunol 31: 891-899.

14- Fabris C, Falleti E, Cussigh A, Bitetto D, Fontanini E, Bignulin S et al (2011) IL-28B rs $12979860 \mathrm{C} / \mathrm{T}$ allele distribution in patients with liver cirrhosis: role in the course of chronic viral hepatitis and the development of HCC. J Hepatol 54:716-722.

15-Noureddin M, Wright EC, Alter HJ, Clark S, Thomas E, Chen R et al (2013) Association of IL28B genotype with fibrosis progression and clinical outcomes in patients with chronic hepatitis C: a longitudinal analysis. Hepatology 58:1548-1557. 
16- Shousha HI, Awad AH, Omran DA, Elnegouly MM, Mabrouk M (2018) Data mining machine learning algorithms using IL28B genotype and biochemical markers best predicted advanced liver fibrosis in chronic HCV. Japanese journal of infectious diseases 71 (1): 51-57.

17- D’Ambrosio R, Aghemo A, De Francesco R, Rumi MG, Galmozzi E, De Nicola S, et al (2014) The association of IL28B genotype with the histological features of chronic hepatitis C is HCV genotype dependent. Int J Mol Sci 15: $7213-7224$.

18- Marabita F, Aghemo A, De Nicola S, Rumi MG, Cheroni C, Scavelli R, et al (2011) Genetic variation in the interleukin-28B gene is not associated with fibrosis progression in patients with chronic hepatitis $\mathrm{C}$ and known date of infection.

Hepatology 54:1127-1134.

19- Bochud PY, Bibert S, Kutalik Z, Patin E, Guergnon J, Nalpas B, et al (2012) IL28B alleles associated with poor hepatitis C virus $(\mathrm{HCV})$ clearance protect against inflammation and fibrosis in patients infected with non-1 HCV genotypes. Hepatology 55: 384-394.

20- Di Marco V, Bronte F, Calvaruso V, Capra M, Borsellino Z, Maggio A, et al (2012) IL28B polymorphisms influence stage of fibrosis and spontaneous or interferon-induced viral clearance in thalassemia patients with hepatitis $C$ virus infection. Haematologica 97: 679-686.

21- Ge D, Fellay J, Thompson AJ, Simon JS, Shianna KV, Urban TJ, et al (2009) Genetic variation in IL28B predicts hepatitis C treatment-induced viral clearance. Nature 461: 399-401.

22- Thomas DL, Thio CL, Martin MP, Qi Y, Ge D, O’Huigin C, et al (2009) Genetic variation in IL28B and spontaneous clearance of hepatitis $\mathrm{C}$ virus. Nature 461: 798-80

23- Abe H, Ochi H, Maekawa T, Hayes CN, Tsuge M, Miki D, et al (2010) Common variation of IL28 affects gamma-GTP levels and inflammation of the liver in chronically infected hepatitis C virus patients. J Hepatol 53: 439-443

24- Rembeck K, Alsiö A, Christensen PB, Färkkilä M, Langeland N, Buhl MR, et al 2012) Impact of IL28B-related single nucleotide polymorphisms on liver histopathology in chronic hepatitis C genotype 2 and 3. PLoS ONE 7: e29370

25- Thomas E, Gonzalez VD, Li Q, Modi AA, Chen W, Noureddin M, et al (2012). HCV infection induces a unique hepatic innate immune response associated with robust production of type III interferons. Gastroenterology 142: 978-988

26- Watanabe T, Sugauchi F, Tanaka Y, Matsuura K, Yatsuhashi H, Murakami S, et al (2013) Hepatitis C virus kinetics by administration of pegylated interferon- $a$ in human and chimeric mice carrying human hepatocytes with variants of the IL28B gene. Gut 62(9): 1340-1346.

27- Zhang Y, Zhu SL, Chen J, Li LQ (2016) Meta-analysis of associations of interleukin-28B polymorphisms rs8099917 and rs12979860 with development of hepatitis virus-related hepatocellular carcinoma. Onco Targets Ther 9: 3249-3257

28- Khan AJ, Saraswat VA, Ranjan P, Parmar D, Negi TS, Mohindra S (2019) Polymorphism in interferon $\lambda 3 /$ interleukin-28B gene and risk to noncirrhotic chronic hepatitis $C$ genotype 3 virus infection and its effect on the response to combined daclatasvir and sofosbuvir therapy. Journal of medical virology 91 (4): 659-667.

29- Salum GM, Dawood RM, el-Meguid MA, Ibrahim NE, Aziz AOA, El Awady MK (2019) Correlation between IL28B/TLR4 genetic variants and HCC development with/without DAAs treatment in chronic HCV patients. Genes \& Diseases 5(4): 1910.1016/j.gendis.2019.05.004DIO:

30- Hanno AFF, Mohiedeen KM, Alshayeb AF, Deghedy A (2014) HCV RNA in peripheral blood mononuclear cells (PBMCs) as a predictor of the response to antiviral therapy in chronic hepatitis C. Alexandria Journal of Medicine 50: 317- 322. 
31- Elzahaby AAA, Soliman GMM, Korany MA, Eltiby DM, El Awady MK (2017) Association Between Post Treatment Existence Of HCV/ RNA Positive Strand And/Or Negative Strand In The PBMCs and HCV Relapse. Journal of the Egyptian Society of Parasitology 47(2): 323-330

32- Abd Alla MDA, Dawood RM, Rashed HA, Farrag G, Ammar IAE, Mahmoud MMA, et al (2021) Treatment of Hepatitis C virus (HCV) by Direct Acting Antivirals (DAAs) Plus Ribavirin Eliminates Intra-Peripheral Blood Mononuclear Cells (PBMCs) Viral RNA and Reduces Virologic Relapse in Diverse Hepatic Parenchymal Changes. Journal Archives of Virology 166(4), 1071-1081, DOI 10.1007/s00705-021-04969-4

33- Hashmi AH, Husnain MA, Farooq A, Khalid K, Shafique S, Adeel K, et al (2018) IL28B is An Irrelevant Prognostic Factor for HCV in the Era of Highly Effective DAAs. J Virol Antivir Res 7 (2): 1-4. doi: 10.4172/2324-8955.1000186

34- Chomczyński P, Sacchi N (1987) Single-step method of RNA isolation by acid guanidinum thiocyanate-phenolchlotoform extraction. Anal Biochem 162: 156-159

35- Zaman N, Asad MJ, Raza A, Raja GK, Akhter S, Mahmood M, et al (2014) Presence of HCV RNA in peripheral blood mononuclear cells may predict patient $\$ s response to interferon and ribavirin therapy. Ann Saudi Med 34 (5): 401-406.

36- Abd Alla MDA, Elibiary SA, Wu GY, El-Awady MK (2017) Occult HCV infection (OCI) diagnosis in cirrhotic and noncirrhotic naïve patients by intra-PBMC nested viral rNA PCR. J Clin \& Transl Hepatol 5: 319-326.

37- Abd Alla MDA, El Awady MK, Dawood RM, Elhawary MA, Al-Azhari, SS, Galal ASG (2018) Hepatitis C virus serologic relapse after treatment with direct-acting antivirals is dependent on viral RNA levels in peripheral blood mononuclear cells and the grade of liver cirrhosis. Archives of virology 163(10): 2765-2774

38- El-Awady MK, Abdel Rahman MM, Ismail SM, Amr KS, Omran M, Mohamed SA (2003) Prediction of relapse after interferon therapy in hepatitis $C$ virus-infected patients by the use of triple assay. J Gastroenterol Hepatol 18: 68-7339.

39- Wahab EA, Fathy T, Saber S, Ahmad HS (2017) Hepatic Elastography And Fib-4 Score Versus Liver Biopsy For Assessment Of Liver Fibrosis In Chronic Hcv Patients. Zagazig University Medical Journal 21: 1-11.

40- Abd Alla, MDA., \& El Awady MK (2017) Hepatitis C virus RNA strands detection in peripheral blood mononuclear cells legitimizes virus eradication in negative serum PCR naïve and post-treatment patients. J Clin\&Transl. Hepatol 5:1-8.

41- Abd Alla MDA, Elibiary SA, Elshaboury RH, Wu GY, Dawood RM, El Awady MK (2018) HCV Therapy follow-up fractionation (CTF2) by intra-PBMC nested RNA PCR recognizes early virologic response and relapse. $J$ clin and trans hepatology 6(2): 1-8.

\section{Figures}




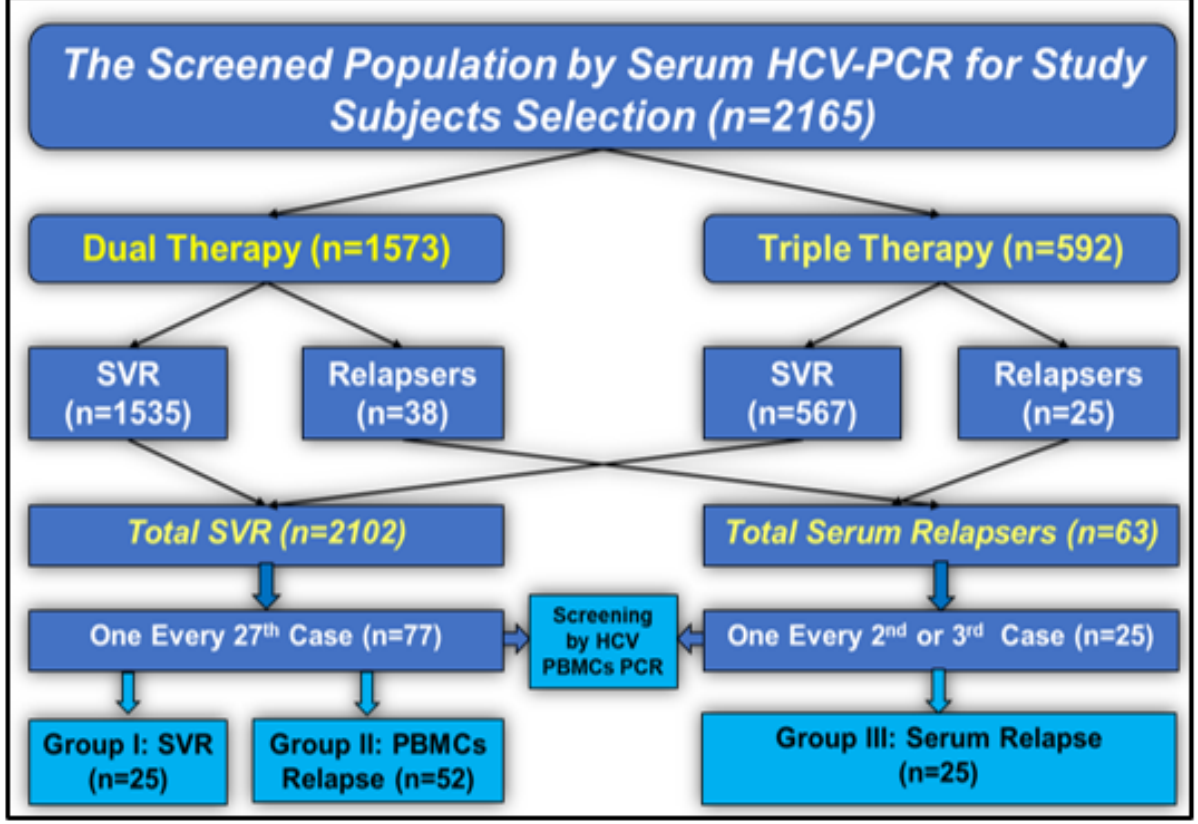

\section{Figure 1}

Grouping of the randomly selected study populations at the end of the 12th week after completing a full DAAs treatment course. Subjects in group I had negative serum and PBMCs-PCRs; those in group II showed positive solitary intracellular HCV-PCR with negative serum viral PCR; cases in group III presented with positive serum HCV-RNA by PCR. Dual therapy = SOF+DAC; Triple therapy = SOF+DAC+RBV, SVR=Sustained Virologic Response.

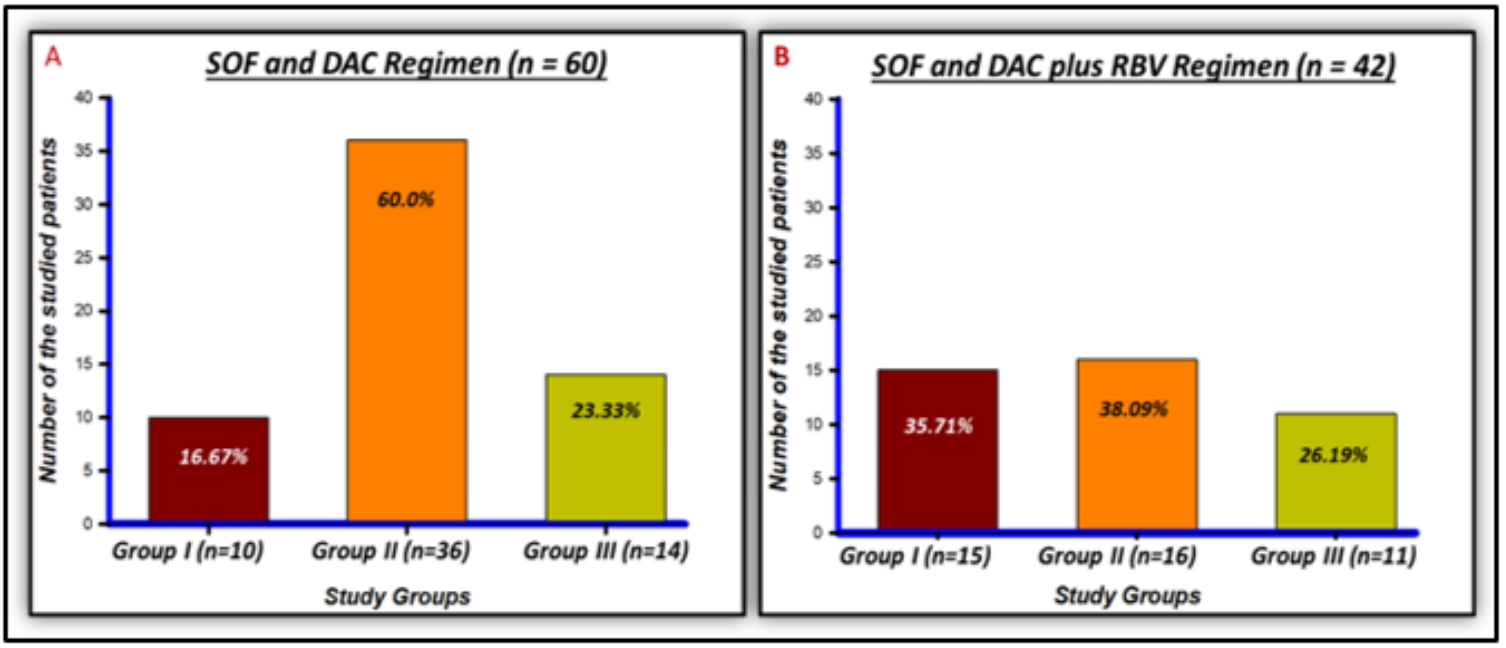

Figure 2

A and B. Evaluation of SOF / DCV \pm RBV regimen administration rates in population of each study group. Data analysis revealed the following: - 1) group II had the highest administration rate of dual therapy compared to group I and group III 2) Insignificant difference in triple therapy intake in the three groups when compared to each other 3) Comparison of dual with triple therapeutic regimens within each group revealed increasing frequency of triple in group I and dual in group II with insignificant difference between the two regimens in group III. The above-mentioned findings verified dual therapy as a suspected precipitating factor in cellular relapse. 


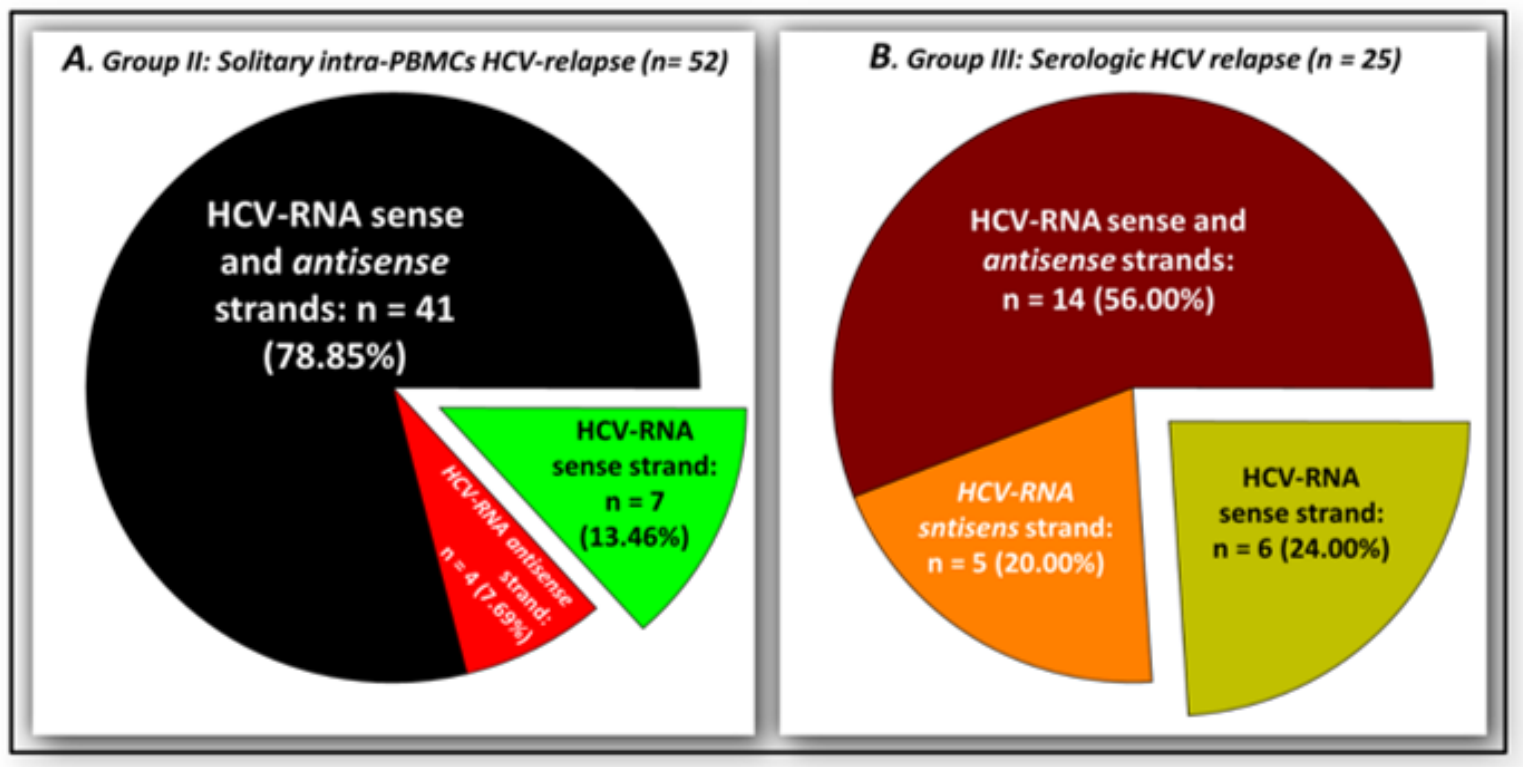

Figure 3

3A and B. Frequency of intracellular replicative HCV-RNA genomic antisense compared to the non-replicative antigenic sense strands regardless to the viremic status. There was highly significant HCV replication in PBMCs in group II and III as indicated by the presence of HCV-RNA antisense compared to the presence of solitary sense strands. The presence of intracellular HCV antisense RNA strand was qualified as a solid prove of viral replication regardless to viremia.

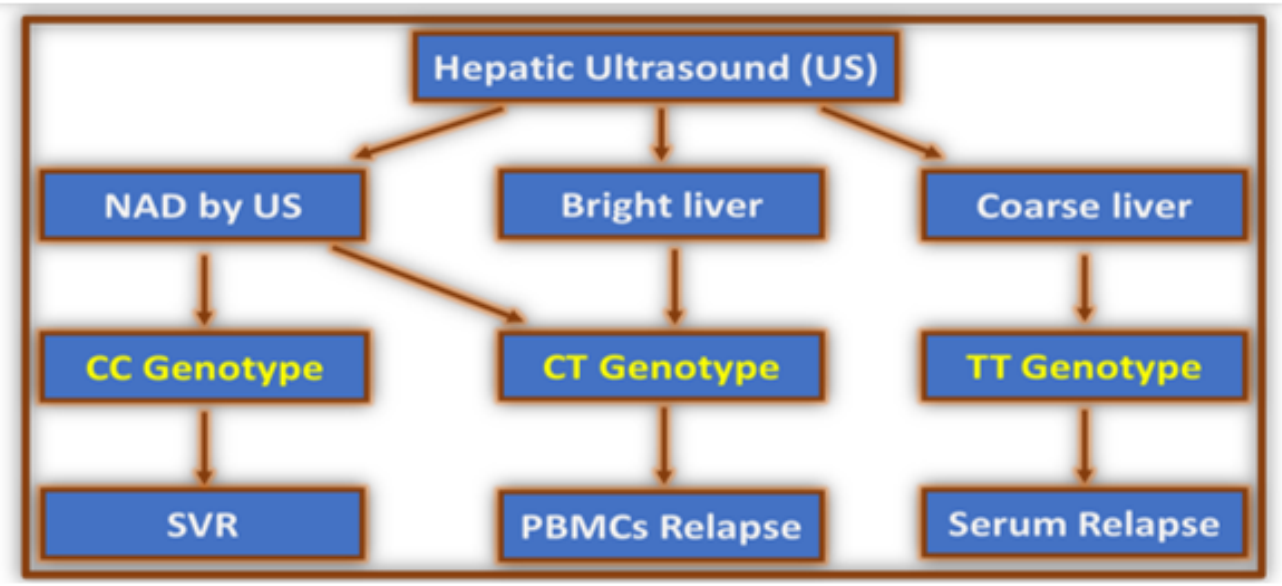

\section{Figure 4}

Relationship of IL28B gene SNPS with viral relapse in various grades of hepatic parenchymal changes after treating $\mathrm{CHCV}$ infection with DAAs. The wild CC nucleotides were dominant in the SVR when hepatic tissues looked normal by US, while CT SNP was associated with PBMCs relapse when hepatic parenchyma locked normal or bright (fibrotic = early changes), and TT SNP was more frequent in serum relapse when liver tissues were cirrhotic. NAD, no abnormality detected; $\mathrm{CHCV}$, Chronic HCV; SVR, sustained virologic response. 


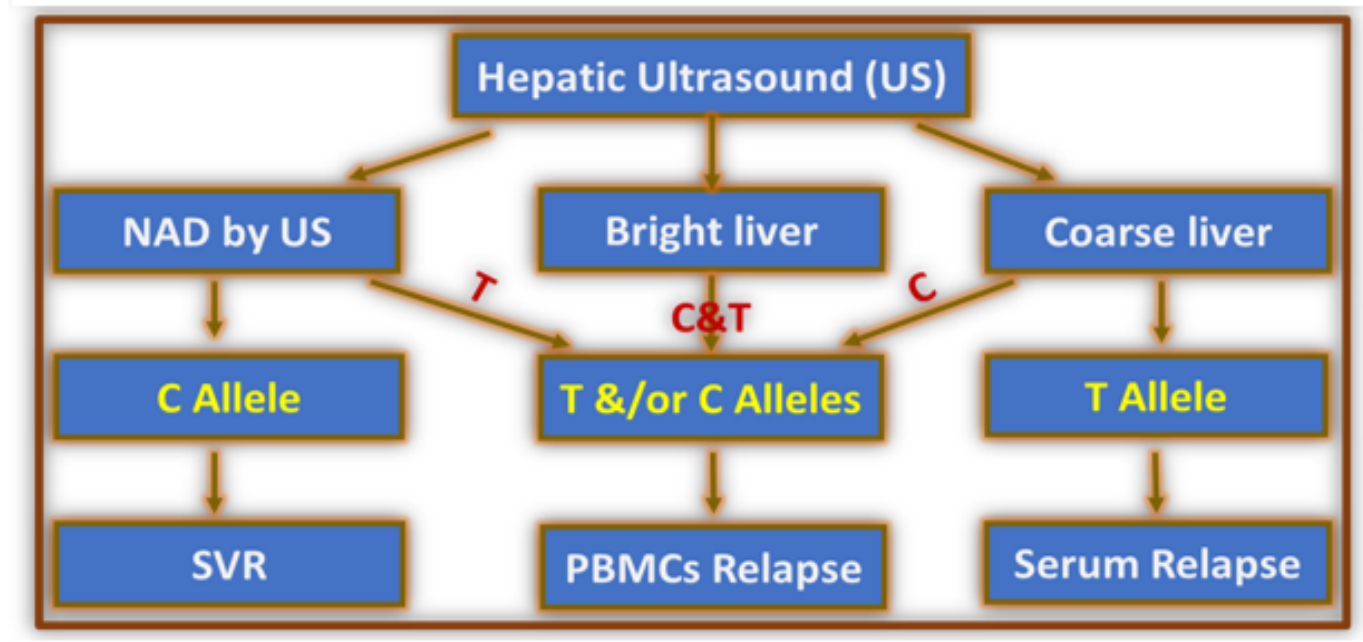

\section{Figure 5}

Distribution of IL28B gene C and T alleles in SVR and HCV relapse with correlation to grades of hepatic parenchymal changes. When hepatic ultrasound (US) concluded no abnormality detected (NAD), the $C$ allele was dominant in SVR, while T allele was associated with PBMC-HCV relapse. In bright hepatic parenchyma by US, both $\mathrm{C}$ and $\mathrm{T}$ alleles were predominant in association with PBMCs HCV relapse. While in coarse liver tissues by US, there was predominant recognition of $\mathrm{T}$ allele in HCV serum relapse and frequent detection of $\mathrm{C}$ allele in persistent HCV-RNA in PBMCs (cellular relapse vs non-response). $\mathrm{CHCV}$, chronic $\mathrm{HCV}$. 